\title{
Commentary \\ Improving survival by increasing lung edema clearance: is airspace delivery of dopamine a solution?
}

\author{
Ariel Jaitovich and Jacob lasha Sznajder
}

Division of Pulmonary and Critical Care Medicine, Feinberg School of Medicine, Northwestern University, Chicago, Illinois, USA

Corresponding author: Jacob I Sznajder, j-sznajder@northwestern.edu

Published: 15 April 2008

Critical Care 2008, 12:135 (doi:10.1186/cc6825)

This article is online at http://ccforum.com/content/12/2/135

(c) 2008 BioMed Central Ltd

See related research by Chamorro-Marin et al., http://ccforum.com/content/12/2/R39

\begin{abstract}
In this issue of Critical Care Chamorro-Marin and coworkers provide new evidence that dopamine instilled into airspaces is beneficial in a rat model of ventilator-induced lung injury. This study is important because it is the first to explore the effects of dopamine on survival, albeit short term. The delivery of dopamine into the airspaces in vivo is also novel and builds upon previous studies describing the mechanisms by which dopamine exerts its effect by upregulating active $\mathrm{Na}^{+}$transport in the lungs. Dopamine appears to increase active $\mathrm{Na}^{+}$transport via activation of amiloridesensitive sodium channels and the basolateral $\mathrm{Na}^{+} / \mathrm{K}^{+}$-ATPase within minutes, and it has been shown to be effective in normal lungs and several models of lung injury. This information is relevant to current clinical trials exploring the effects of alveolar fluid clearance stimulation in patients with acute lung injury.
\end{abstract}

In this issue of Critical Care Chamorro-Marin and coworkers [1] reported a significant decrease in short-term ventilatorinduced lung injury (VILI)-related mortality by intratracheal administration of dopamine in rats subjected to injurious (high tidal volume) mechanical ventilation. This finding is interesting and has potentially relevant implications for mechanically ventilated patients with acute lung injury.

VILI occurs when the lung tissue is disrupted by high tidal volumes during mechanical ventilation, leading to pulmonary edema and hypoxemia [2]. The lung injury and edema formation were proposed to be due to activation of intracellular signals that initiate/amplify an injurious cascade that leads to systemic inflammation and dysfunction of other organs [2]. Many strategies have been tested with the aim being to decrease the deleterious effects of VILI. The one approach with more acknowledged success was that evaluated in the the US National Institutes of Health-sponsored ARDSnet study, which showed that ventilating patients with acute respiratory distress syndrome with a low tidal volume strategy (about $6 \mathrm{ml} / \mathrm{kg}$ ) decreased mortality in this patient population. Other approaches such as high levels of positive endexpiratory pressure, prone positioning, and recruitment maneuvers appear to improve hypoxemia but have not yet been shown to reduce mortality [3]. Despite the incorporation of these approaches into clinical practice, the incidence of VILI and mortality in patients with pulmonary edema remains high.

In their study in rats, Chamorro-Marin and coworkers [1] found that administration of dopamine in airspaces exposed to injurious (high tidal volume) mechanical ventilation resulted in lower lung wet weight/dry weight ratio (a gravimetric estimate of pulmonary edema) and improved survival in the dopamine-treated group. As such, the study provides interesting and novel information. For example, the use of very high levels of tidal volume which cause lung injury may suggest that the dopamine instillation strategy could be of benefit, particularly in patients who cannot tolerate low tidal volume, as is the case for a small proportion of patients who require ventilation with injuriously high tidal volumes. Also, as shown in Table 2 of the report by Chamorro-Marin and coworkers [1], dopamine instilled into rat airspaces did not appear to cause deleterious hemodynamic effects, as are sometimes observed during systemic administration of dopamine, particularly at higher doses. A limitation of the study is that although relevant, the research focuses on a very short period of time and further studies would be of benefit to validate these interesting observations. As mentioned by the investigators, research in larger animals, reflecting the situation in patients to a greater extent, would be of significant interest.

An important question highlighted by this research is why and how does dopamine exert its effects in the lungs of animal models (and hopefully in patients)? Dopamine has been

$\mathrm{VILI}=$ ventilator-induced lung injury 
reported to accelerate clearance of lung edema in normal and VILI lung models via activation of $D_{1}$ and $D_{2}$ receptors [4-6]. These reports demonstrated that activating dopaminergic $D_{1}$ receptors increases, within minutes, $\mathrm{Na}^{+} / \mathrm{K}^{+}$-ATPase activity by promoting the recruitment of $\mathrm{Na}^{+}$pump proteins from intracellular endosomal compartments into the plasma membrane of alveolar epithelial cells via specific signaling pathways that involve cell microtubules and actin cell cytoskeleton [7-9]. Dopamine has been also shown to activate amiloride-sensitive $\mathrm{Na}^{+}$channels in alveolar epithelial type I cells, which cover most of the alveolar epithelial surface area [10].

Interestingly, activating dopaminergic $D_{2}$ receptors has a different effect on the $\mathrm{Na}^{+} / \mathrm{K}^{+}$-ATPase, which includes stimulation of mitogen-activated kinase ERK1/2 (extracellular signal-regulated kinase-1/2), leading to increased transcription/translation of the $\mathrm{Na}^{+} / \mathrm{K}^{+}$-ATPase proteins by 24 hours [6]. It thus appears that dopamine, by increasing initially the $\mathrm{Na}^{+} / \mathrm{K}^{+}$-ATPase protein abundance at the plasma membrane and later by increasing protein translation, leads to higher $\mathrm{Na}^{+} / \mathrm{K}^{+}$-ATPase activity and hence increased edema clearance.

The other important issue is that dopamine in this and in some previous studies was delivered intratracheally, which decreases the potentially confounding systemic effects, thus offering a therapeutic alternative. The more localized approach to delivering $\beta$-adrenergic agonists to lung epithelium has been reported to be beneficial in patients with pulmonary edema [11] and is now the focus of large multicenter clinical trials. The study by Chamorro-Marin and coworkers [1] provides further evidence, albeit in an animal model, that direct therapy with yet another inexpensive drug (dopamine) delivered to the lungs can be of benefit in terms of improving oxygenation and short-term survival.

In summary, Chamorro-Marin and coworkers [1] present interesting data in an animal model of lung injury that suggest a beneficial effect of dopamine delivered directly to lung epithelium, which may be applied as an adjuvant measure to counteract the deleterious effects of VILI; those investigators also provide valuable insight into the pathophysiology of VILI. Delivering pharmacologic agents directly to the bronchial and alveolar epithelium may become a valid therapeutic strategy for treating patients with pulmonary edema and avoiding systemic effects of compounds that are relatively inexpensive and with which physicians are quite familiar.

\section{Competing interests}

The author declares that they have no competing interests.

\section{Acknowledgement}

Supported in part by HL-48129, and PO1 HL-71643.

\section{References}

1. Chamorro Marin VV, Garcia Delgado MM, Touma Fernandez AA, Aguilar Alonso EE, Fernandez-Mondejar EE: Intratracheal dopamine attenuates pulmonary edema and improves survival after ventilator-induced lung injury in rats. Crit Care 2008, 12:R39.

2. Tremblay LN, Slutsky AS: Pathogenesis of ventilator-induced lung injury: trials and tribulations. Am J Physiol Lung Cell Mol Physiol 2005, 288:L596-L598.

3. Meade MO, Cook DJ, Guyatt GH, Slutsky AS, Arabi YM, Cooper DJ, Davies AR, Hand LE, Zhou Q, Thabane L, Austin P, Lapinsky S, Baxter A, Russell J, Skrobik Y, Ronco JJ, Stewart TE; Lung Open Ventilation Study Investigators: Ventilation strategy using low tidal volumes, recruitment maneuvers, and high positive end-expiratory pressure for acute lung injury and acute respiratory distress syndrome: a randomized controlled trial. JAMA 2008, 299:637-645.

4. Bertorello A, Sznajder J: The dopamine paradox in lung and kidney epithelia: sharing the same target but operating different signaling networks. Am J Respir Cell Mol Biol 2005, 33: 432-437.

5. Barnard ML, Ridge KM, Saldias F, Gare M, Friedman E, Lecuona E, Guerrero C, Bertorello AM, Katz Al, Sznajder Jl: Stimulation of the Dopamine 1 receptor increases lung edema clearance. Am J Respir Crit Care Med 1999, 160:982-986.

6. Guerrero C, Pesce L, Lecuona E, Ridge KM, Sznajder J: Dopamine activates ERK's in alveolar epithelial cells via RASPKC dependent and GRB2/SOS independent mechanisms. Am J Physiol Lung Cell Mol Physiol 2002, 282:L1099-L1107.

7. Ridge KM, Dada L, Lecuona E, Bertorello A, Katz Al, MochlyRosen D, Sznajder Jl: Dopamine-induced exocytosis of $\mathrm{Na}$, KATPase is dependent on activation of protein kinase C-epsilon and -delta. Mol Biol Cell 2002, 13:1381-1389.

8. Ridge KM, Olivera W, Saldias F, Azzam Z, Horowitz S, Rutschman $\mathrm{DH}$, Factor P, Sznajder Jl: Alveolar type 1 cells express the alpha $2 \mathrm{Na}, \mathrm{K}$-ATPase which contributes to lung liquid clearance. Circ Res 2003, 92:453-460.

9. Bertorello A, Komarova Y, Efendiev R, Pedemonte $\mathrm{CH}$, Leibiger IB, Borisy G, Sznajder Jl: Analysis of $\mathrm{Na}, \mathrm{K}-\mathrm{ATPase}$ motion and incorporation into the plasma membrane in response to $G$ protein-coupled receptor signals in living cells. Mol Biol Cell 2003, 14:1149-1157.

10. Helms MN, Self J, Bao HF, Job LC, Jain L, Eaton DC: Dopamine activates amiloride-sensitive sodium channels in alveolar type I cells in lung slice preparations. Am J Physiol Lung Cell Mol Physiol 2006, 291:L610-L618.

11. Perkins GD, McAuley DF, Thickett DR, Gao F: The beta-agonist lung injury trial (BALTI): a randomized placebo-controlled clinical trial. Am J Respir Crit Care Med 2006, 173:281-287. 